Original research article

\title{
Monocyte/high-density lipoprotein ratio predicts the mortality in ischemic stroke patients
}

\author{
Asli Bolayir ${ }^{a, *, 1}$, Seyda Figul Gokce ${ }^{a, 2}$, Burhanettin Cigdem ${ }^{a, 2}$, \\ Hasan Ata Bolayir ${ }^{b, 3}$, Ozlem Kayim Yildiz ${ }^{a, 2}$, Ertugrul Bolayir ${ }^{a, 3}$, \\ Suat Ahmet Topaktas ${ }^{a, 3}$ \\ ${ }^{a}$ Cumhuriyet University Neurology Department, Sivas, Turkey \\ ${ }^{\mathrm{b}}$ Sivas Numune State Hospital Cardiology Department, Sivas, Turkey
}

\section{A R T I C L E I N F O}

Article history:

Received 1 March 2017

Accepted 14 August 2017

Available online 24 August 2017

Keywords:

Monoycte

High density lipoprotein

Monocyte to high density

lipoprotein ratio

Acute ischemic stroke

Mortality

\begin{abstract}
A B S T R A C T
Objective: The inflammatory process is a very important stage in the development and prognosis of acute ischemic stroke (AIS). The monocyte to high-density lipoprotein (HDL) ratio (MHR) is accepted as a novel marker for demonstrating inflammation. However, the role of MHR as a predictor of mortality in patients with AIS remains unclear.

Methods: We retrospectively enrolled 466 patients who were referred to our clinic within the first 24 hours of symptom presentation and who were diagnosed with AIS between January 2008 and June 2016. Four hundred and eight controls of similar age and gender were also included. The patient group was classified into two groups according to 30-day mortality. The groups were compared in terms of monocyte counts, HDL, and MHR values.

Results: The patient group had significantly higher monocyte counts and lower HDL levels; therefore, this group had higher values of MHR compared to controls. Additionally, the monocyte count and MHR value were higher, and the HDL level was lower in non-surviving patients $(p<0.001)$. The MHR value was also observed as a significant independent variable of 30-day mortality in patients with AIS $(p<0.001)$. The optimum cut-off value of MHR in predicting the 30-day mortality for patients with AIS was 17.52 (95\% CI 0.95-0.98).

Conclusion: Our study demonstrated that a high MHR value is an independent predictor of 30-day mortality in patients with AIS.
\end{abstract}

(c) 2017 Polish Neurological Society. Published by Elsevier Sp. z o.o. All rights reserved.

\footnotetext{
* Corresponding author.

E-mail addresses: asliarslanturk@gmail.com (A. Bolayir), seydafigul_gokce@hotmail.com (S.F. Gokce), drbcigdem@gmail.com (B. Cigdem), habolayir@hotmail.com (H.A. Bolayir), ozlemkayim@yahoo.com (O.K. Yildiz), ebol@mynet.com (E. Bolayir), suattopaktas@gmail.com (S.A. Topaktas).

${ }^{1}$ Take the idea for study, planning the methods to generate hypothesis, responsibility for conducting literature search, responsibility for creation of an entire or the substantial part of the manuscript.

2 Take the idea for study, planning the methods to generate hypothesis, responsibility for conducting literature search.

${ }^{3}$ Take the idea for study, reworking the final, before submission version of the manuscript for intellectual content, not just spelling and grammar check.

http://dx.doi.org/10.1016/j.pjnns.2017.08.011

0028-3843/@ 2017 Polish Neurological Society. Published by Elsevier Sp. z o.o. All rights reserved.
} 


\section{Introduction}

Acute ischemic stroke (AIS) is defined as an infarct due to arterial occlusion [1]. It is the most common emergent neurological condition, with a high incidence of mortality and morbidity, especially in the elderly population [1,2]. Among the etiologic factors, large artery atherosclerosis and cardioembolic causes have a great importance. Atrial fibrillation (AF) is the most frequent reason for cardioembolic stroke [2]. Independent of the stroke etiology, there is a growing body of evidence indicating that the inflammatory process is very critical in the development and prognosis of AIS [3].

Macrophages and monocytes are types of cells that play key roles in the release of proinflammatory cytokines and contribute to all stages of inflammation [4,5]. In particular, activated monocytes modulate inflammatory cytokines during the development of chronic inflammation and cardiovascular diseases [6,7]. It is known that high-density lipoprotein (HDL) inhibits the oxidation of low-density lipoprotein (LDL) and protects the endothelium against the destructive effects of LDL [8]. In this way, it is thought that HDL has antiinflammatory effects $[8,9]$. Recent reports have demonstrated that the increased monocyte count to HDL ratio (MHR), which is obtained by dividing the monocyte count by the HDL value, may be a novel predictor of prognosis in cardiovascular diseases [10-12]. To our knowledge, however, no study has evaluated the role of MHR in the process or prognosis of ischemic stroke in the literature.

In this study, our aim was to retrospectively compare the MHR values between patients with AIS and controls and to determine the role of MHR in the 30-day mortality of patients with AIS.

\section{Materials and methods}

\subsection{Study group}

Our study is a single-center retrospective study that included 466 patients who were referred to our clinic within the first $24 \mathrm{~h}$ of symptoms and diagnosed with AIS between January 2008 and June 2016. The medical history, cranial magnetic resonance (MR), or computed tomography (CT) imaging findings showed the newly occurred ischemic lesion, and the neurological examination findings of patients were used in order to determine the definitive diagnosis of AIS. There were no restrictions regarding sex and age among the patients. Exclusion criteria were systematic acute/chronic inflammatory/autoimmune or infectious diseases, chronic connective tissue diseases, hematological disorders, cancer, severe liver, kidney or heart failure, acute coronary syndrome within the past three months, prior acute myocardial infarction, a history of major surgery or trauma, and chronic alcohol abuse. The patient group was divided into two subgroups according to the 30-day patient mortality. The patients in the first group were survivors past 30 days, and patients in the second group were patients who died within 30 days after AIS.

The control group consisted of 408 patients who were ageand gender-matched and gave blood samples for reasons other than AIS between January 2008 and September 2016. These patients did not suffer from any uncontrolled systemic diseases such as diabetes mellitus, hypertension, cardiovascular diseases or cancer.

All patients included in the current study were examined and investigated in terms of parameters such as age, gender, diabetes mellitus (defined as the fasting blood glucose level above $126 \mathrm{mg} / \mathrm{dl}$ and/or the use of antidiabetic therapy), hypertension (defined as the systolic blood pressure above $140 \mathrm{mmHg}$ and/or the diastolic blood pressure above $90 \mathrm{mmHg}$, or the use of antihypertensive therapy), hyperlipidemia (defined as the fasting total cholesterol value above $200 \mathrm{mg} / \mathrm{dl}$ and/or the triglyceride value above $150 \mathrm{mg} / \mathrm{dl}$ ), smoking history (current smoker or having quit in the last 6 months), and body mass index (BMI).

Approval by the ethics committee of Cumhuriyet University was obtained for the study.

\subsection{Evaluation of biochemical and hematological parameters}

Blood samples of patients were collected within the first $24 \mathrm{~h}$ following AIS. Dry tubes were used for the biochemical analysis, and EDTA tubes were used for the hematological test. Whole blood counts of patient and control groups were analyzed with a Mindray BC-6800 device using Diagon Kits. Biochemical analyses were performed with a Beckman Coulter AU5800 device (Beckman Coulter Inc, Hialeah, Florida) using kits produced by the same company via a fully automatic nephelometric method.

\subsection{Statistical analysis}

Data obtained from this study was evaluated by using the SPSS 22.0 program. Continuous data were expressed as the mean \pm standard deviation; categorical data were expressed as percent (\%). Data were evaluated with the KolmogorovSmirnov test in terms of normal distribution. The use of an independent $\mathrm{T}$-test for the analysis of continuous data showing normal distribution and a Mann-Whitney U-test for the analysis of variables not showing normal distribution were planned. However, continuous data obtained from two different groups did not show normal distribution, therefore, the Mann-Whitney U-test was used for the analysis. Logistic regression analysis and the chi-square test were used to determine the independent risk factors for the 30-day mortality of patients with AIS. Receiver operating characteristic curve (ROC) analysis was used for determining the optimum cut-off value of MHR for predicting the 30-day mortality of patients with AIS. The statistical significance level was accepted as $p<0.05$.

\section{Results}

Comparison of the patient and control groups in terms of baseline demographic characteristics revealed that there was no significant difference between the two groups in terms of age, gender, diabetes mellitus status, hypertensive status, BMI values, statin use, and smoking status. The mean age of the 


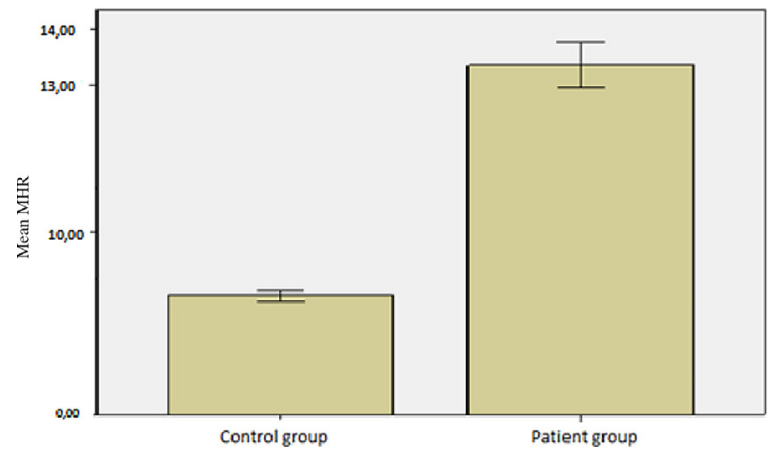

Fig. 1 - Mean MHR values in control and patient groups.

patients was $77.09 \pm 6.7$, while the control group was 77.35 \pm 9.6 years.

When the patient and control groups were compared in terms of laboratory parameters, there was no significant difference between the two groups in terms of creatinine, hemoglobin, LDL and total cholesterol levels $(p=0.12, p=0.59$, $p=0.58$, and $p=0.59$, respectively). On the other hand, there were significant differences between the two groups in terms of uric acid, glucose, mean platelet volume (MPV), C-reactive protein (CRP), platelet, monocyte, lymphocyte, neutrophil and white blood cell (WBC) counts, HDL and MHR values (Fig. 1). While uric acid, glucose, MPV, CRP, platelet, monocyte, neutrophil and WBC counts, and the MHR values were higher in the patient group, the lymphocyte count and HDL level were significantly higher in the control group (Table 1).

Patients with ischemic stroke were classified into two groups according to the 30-day mortality. The first group survived, while patients in the second group died within 30 days after AIS. The comparison of the two groups in terms of monocyte count, HDL level and MHR value demonstrated that monocyte count and MHR value of the second group were statistically higher, while the HDL level was statistically lower compared to the first group $(p<0.001)$ (Table 2$)$.

The determination of risk factors related to the 30-day mortality of AIS patients included age, gender, presence of diabetes and hypertension, cigarette use, HDL, LDL, total cholesterol, hemoglobin, CRP, MHR and uric acid, which were used as independent variables. Application of multivariate analyses on these parameters showed that uric acid, CRP, and MHR values were statistically significant independent variables for the prediction of 30-day mortality in AIS patients (Table 3).

In addition, receiver operating characteristic curve (ROC) analysis was used for determining the optimum cut-off MHR value for predicting 30-day mortality in AIS patients. The area under the curve (AUC) value was calculated as $0.97(95 \%$ confidence interval (CI) 0.95-0.98). The cut-off MHR value was observed as 17.52 with a sensitivity of $94.4 \%$ and a specificity of $84.8 \%$ (Fig. 2).

\section{Discussion}

This is the first study to demonstrate that patients with AIS had higher monocyte counts, lower HDL levels, and therefore, higher values of MHR compared to controls. MHR values above 17.52 seem to be an independent risk factor for predicting the 30-day mortality of patients with AIS.

Inflammation plays important roles in all pathophysiological stages of AIS [4,5]. It is very significant in both the development of AIS and in the post-AIS process. The components of the immune system lead to the progression of AIS in various ways. Interactions between lipids and the various stages of the immune system stimulate premature atherogenes and adverse atrial electrical and/or structural remodeling, which may represent a prerequisite for $\mathrm{AF}[4,11]$.

Macrophages and monocytes could play a role in the progress of both atherosclerosis and AF. Endothelial dysfunction is the first step in the subsequent development of atherosclerosis. After endothelial dysfunction, mononuclear cells such as monocytes and $\mathrm{T}$ lymphocytes attach to the endothelium. They first attach loosely, and then they adhere tightly to the endothelium and migrate to the subendothelial space. Afterwards, monocytes mature into macrophages, which promote inflammation and destruction of extracellular matrix. The macrophages then differentiate into foam cells by taking oxidized LDL and other lipids via the scavenger receptors, SR-A and CD-36 [12]. Foam cells that turn into fatty streaks secrete proinflammatory cytokines that stimulate the local inflammatory response around the lesion. These include matrix metalloproteinases, tissue factors, and growth factors that initiate smooth muscle replication involved in the progression of the lesion. Increased activity of metalloproteinases promotes the digestion of the internal elastic lamina, which subsequently increases the tendency of plaques to rupture [13]. Tissue factors are frequently located within macrophage-rich areas within the necrotic center of the plaque. Thrombosis occurs when tissue factors come in contact with circulating blood, resulting in occlusion of the related artery [14]. As can be observed, macrophages and their precursor cells, the monocytes, play important roles in all phases of atherosclerosis from fatty streak formation to plaque rupture, and even in the development of AIS. An increase in the number of tissue macrophages and circulating monocytes, which are the source of foam cells, is supposed to be an indicator of the development of new plaques [15].

Additionally, the production of several cytokines (like tumor necrosis factor (TNF)-a, interleukin (IL)-1, IL-6, platelet-derived endothelial cell growth factor, transforming growth factor (TGF)- $\alpha$ and- $\$$, macrophage colony-stimulating factor, and insulin-like growth factor) are induced after monocytes adhere to the endothelial cell surface and extravasate into the damaged tissue [16]. The secretions of MMP-9 and TGF- $B$, which are induced by IL-1b secretion from macrophages, stimulate fibroblast proliferation [16]. Likewise, it has been reported that leukocyte activation, especially monocyte activation, was present in post-operative AF [17]. Therefore, monocytes, which have a long circulation half-life, and macrophages, which can transform into long-living tissue macrophages, could play a role in the inflammatory response leading to AF. In accordance with these two conditions, in our study, we found that the monocyte count was significantly higher in patients with AIS compared to the control group.

After arterial occlusion in brain tissue, the microglia, which are brain resident macrophages, are activated within minutes. 
Table 1 - Comparison of baseline demographic, clinical, and laboratory characteristics of the control and the patient groups.

\begin{tabular}{|c|c|c|c|c|}
\hline & Control group $(n=408)$ & Patient group $(n=466)$ & $X^{2}$ value & $p$ values \\
\hline Male, $n(\%)$ & $184(45.1 \%)$ & $208(44.6 \%)$ & 0.01 & 0.92 \\
\hline HT Presence, $n(\%)$ & $304(74.5 \%)$ & 378 (81.1\%) & 2.76 & 0.09 \\
\hline DM Presence, $n(\%)$ & $150(36.8 \%)$ & $148(31.8 \%)$ & 1.21 & 0.27 \\
\hline Smoking, $n(\%)$ & $184(45.1 \%)$ & $170(36.5 \%)$ & 3.35 & 0.07 \\
\hline Statin use, $n(\%)$ & $214(52.5 \%)$ & $228(48.9 \%)$ & 0.54 & 0.46 \\
\hline Age (mean $\pm \mathrm{SD}$ ) & $77.09 \pm 6.70$ & $77.35 \pm 9.56$ & & 0.25 \\
\hline$(\min -\max )$ & $(61-92)$ & $(34-98)$ & & \\
\hline BMI $\left(\mathrm{kg} / \mathrm{m}^{2}\right)($ mean $\pm \mathrm{SD})$ & $26.39 \pm 3.26$ & $25.86 \pm 4.03$ & & 0.18 \\
\hline$(\min -\max )$ & $(21-35)$ & $(17-35)$ & & \\
\hline Subgroups according to etiology, $n(\%)$ & - & & & \\
\hline Large artery atherosclerosis & - & $230(49.4 \%)$ & & \\
\hline Cardioembolic causes & - & $166(35.6 \%)$ & & \\
\hline Lacunar infarct & - & $51(10.9 \%)$ & & \\
\hline Others & - & $19(4.1 \%)$ & & \\
\hline $\begin{array}{l}\mathrm{HDL}(\mathrm{mg} / \mathrm{dL})(\text { mean } \pm \mathrm{SD}) \\
(\min -\max )\end{array}$ & $\begin{array}{l}52.81 \pm 28.96 \\
(35-92)\end{array}$ & $\begin{array}{l}45.93 \pm 15.61 \\
(28-75)\end{array}$ & & $<0.001$ \\
\hline $\begin{array}{l}\mathrm{LDL}(\mathrm{mg} / \mathrm{dL})(\operatorname{mean} \pm \mathrm{SD}) \\
(\min -\max )\end{array}$ & $\begin{array}{l}108.13 \pm 7.81 \\
(75-142)\end{array}$ & $\begin{array}{l}106 \pm 7.46 \\
(77-152)\end{array}$ & & 0.58 \\
\hline $\begin{array}{l}\text { TotalChol }(\mathrm{mg} / \mathrm{dL})(\text { mean } \pm \mathrm{SD}) \\
\text { (min-max) }\end{array}$ & $\begin{array}{l}179.45 \pm 37.51 \\
(129-267)\end{array}$ & $\begin{array}{l}175.02 \pm 49.13 \\
(38-328)\end{array}$ & & 0.59 \\
\hline $\begin{array}{l}\text { Uric acid }(\text { mean } \pm S D) \\
(\text { min-max })\end{array}$ & $\begin{array}{l}4.04 \pm 0.83 \\
(2.1-6.3)\end{array}$ & $\begin{array}{l}6.41 \pm 1.43 \\
(3.8-11.3)\end{array}$ & & $<0.001$ \\
\hline $\begin{array}{l}\text { Creatine }(\mathrm{mg} / \mathrm{dL})(\text { mean } \pm \mathrm{SD}) \\
(\min -\max )\end{array}$ & $\begin{array}{l}0.80 \pm 0.12 \\
(0.56-1.2)\end{array}$ & $\begin{array}{l}0.78 \pm 0.12 \\
(0.56-1.2)\end{array}$ & & 0.12 \\
\hline $\begin{array}{l}\mathrm{Hb}(\mathrm{g} / \mathrm{dL})(\operatorname{mean} \pm \mathrm{SD}) \\
(\min -\max )\end{array}$ & $\begin{array}{l}14.32 \pm 1.28 \\
(10.2-17.7)\end{array}$ & $\begin{array}{l}14.18 \pm 1.89 \\
(7.8-19)\end{array}$ & & 0.59 \\
\hline $\begin{array}{l}\text { Glucose }(\mathrm{mg} / \mathrm{dL})(\text { mean } \pm \mathrm{SD}) \\
(\min -\max )\end{array}$ & $\begin{array}{l}123.42 \pm 42.59 \\
(66-248)\end{array}$ & $\begin{array}{l}127.53 \pm 26.95 \\
(67-212)\end{array}$ & & $<0.001$ \\
\hline $\begin{array}{l}\text { MPV (fL) (mean } \pm \text { SD) } \\
\text { (min-max) }\end{array}$ & $\begin{array}{l}8.89 \pm 0.86 \\
(7.1-10.5)\end{array}$ & $\begin{array}{l}9.45 \pm 1.02 \\
(6.8-12.9)\end{array}$ & & $<0.001$ \\
\hline $\begin{array}{l}\mathrm{CRP}(\mathrm{mg} / \mathrm{dl})(\mathrm{mean} \pm \mathrm{SD}) \\
(\min -\max )\end{array}$ & $\begin{array}{l}5.38 \pm 2.46 \\
(1.1-10.1)\end{array}$ & $\begin{array}{l}10.19 \pm 7.52 \\
(2.6-18.4)\end{array}$ & & $<0.001$ \\
\hline $\begin{array}{l}\text { Platelet }\left(\times 10^{3} / \mathrm{L}\right)(\text { mean } \pm \mathrm{SD}) \\
(\min -\max )\end{array}$ & $\begin{array}{l}207.52 \pm 41.63 \\
(112-313)\end{array}$ & $\begin{array}{l}276.78 \pm 74.90 \\
(20-465)\end{array}$ & & $<0.001$ \\
\hline $\begin{array}{l}\text { Monocyte }\left(\times 10^{9} / \mu \mathrm{l}\right)(\text { mean } \pm \mathrm{SD}) \\
(\min -\max )\end{array}$ & $\begin{array}{l}500.44 \pm 94.10 \\
(100-580)\end{array}$ & $\begin{array}{l}608.03 \pm 260.54 \\
(220-1200)\end{array}$ & & 0.002 \\
\hline $\begin{array}{l}\text { Lymphocyte }\left(\times 10^{9} / \mu \mathrm{l}\right)(\text { mean } \pm \mathrm{SD}) \\
\text { (min-max) }\end{array}$ & $\begin{array}{l}1787.26 \pm 510.08 \\
(600-2900)\end{array}$ & $\begin{array}{l}1270.69 \pm 708.29 \\
(100-4900)\end{array}$ & & $<0.001$ \\
\hline Neutrophil $\left(\times 10^{9} / \mu \mathrm{l}\right)($ mean \pm SD) & $\begin{array}{l}4647.06 \pm 1275.05 \\
(2600-8600)\end{array}$ & $\begin{array}{l}6420.04 \pm 3574.70 \\
(1090-20800)\end{array}$ & & $<0.001$ \\
\hline $\begin{array}{l}\text { WBC }\left(\times 10^{9} / \mu \mathrm{l}\right)(\text { mean } \pm \mathrm{SD}) \\
(\min -\max )\end{array}$ & $\begin{array}{l}6937.26 \pm 1935.20 \\
(600-12200)\end{array}$ & $\begin{array}{l}8370.82 \pm 3712.09 \\
(1400-22000)\end{array}$ & & $<0.001$ \\
\hline $\begin{array}{l}\text { MHR (mean } \pm \text { SD) } \\
(\min -\max )\end{array}$ & $\begin{array}{l}9.46 \pm 1.13 \\
(2.1-16.6)\end{array}$ & $\begin{array}{l}13.58 \pm 4.67 \\
(5.2-32.84)\end{array}$ & & $<0.001$ \\
\hline
\end{tabular}

Italic values are used to demonstrate the statistical significance.

Abbreviations: BMI: body mass index; CRP: C-reactive protein; DM: diabetes mellitus; Hb: hemoglobin; HDL: high density lipoprotein; HT: hypertension; LDL: low density lipoprotein; MHR: monocyte to high density lipoprotein ratio; MPV: mean platelet volume; TotalChol: total cholesterol; SD: standard deviation; WBC: white blood cell.

Table 2 - Comparison of the mean monocyte count, HDL level and MHR value in patient group after classification into subgroups according to the mortality within 30-day period.

\begin{tabular}{lccc} 
& Surviving group $(n=378)$ & Non-surviving group $(n=88)$ & $p$ values \\
\hline Monocyte $\left(\times 10^{9} / \mu \mathrm{l}\right)($ mean $\pm \mathrm{SD})$ & $534.13 \pm 10.99$ & $925.46 \pm 56.25$ & $(305-1200)$ \\
$(\min -\mathrm{max})$ & $(220-1030)$ & $37.07 \pm 2.16$ \\
$\mathrm{HDL}(\mathrm{m} / \mathrm{dL})($ mean $\pm \mathrm{SD})$ & $46.22 \pm 1.09$ & $(28-67)$ & $<0.001$ \\
$(\min -\mathrm{max})$ & $(32-75)$ & $18.91 \pm 6.25$ & $<0.001$ \\
MHR $(\operatorname{mean} \pm \mathrm{SD})$ & $12.34 \pm 2.30$ & $(7.64-32.84)$ & $<0.001$ \\
$(\min -\max )$ & $(5.20-23.41)$ & & \\
\hline
\end{tabular}

Italic values are used to demonstrate the statistical significance.

Abbreviations: MHR: monocyte to high density lipoprotein ratio; SD: standard deviation. 
Table 3 - Logistic regression analysis of independent significant variables in the 30-day mortality in AIS.

\begin{tabular}{lccccl} 
& $\beta$ & $\mathrm{SE}$ & $p$ & $\operatorname{Exp}(B)$ & $95 \%$ CI \\
\hline Uric acid & 2.60 & 0.68 & 0.001 & 13.86 & $3.65-52.65$ \\
CRP & 0.63 & 0.18 & 0.001 & 1.88 & $1.32-2.69$ \\
MHR & 1.84 & 0.41 & 0.001 & 6.32 & $2.84-14.04$ \\
\hline
\end{tabular}

Abbreviations: CI: confidence interval; CRP: C-reactive protein; MHR: monocyte to high density lipoprotein ratio; SE: standard error; $\beta$ : regression coefficient.

\section{ROC Curve}

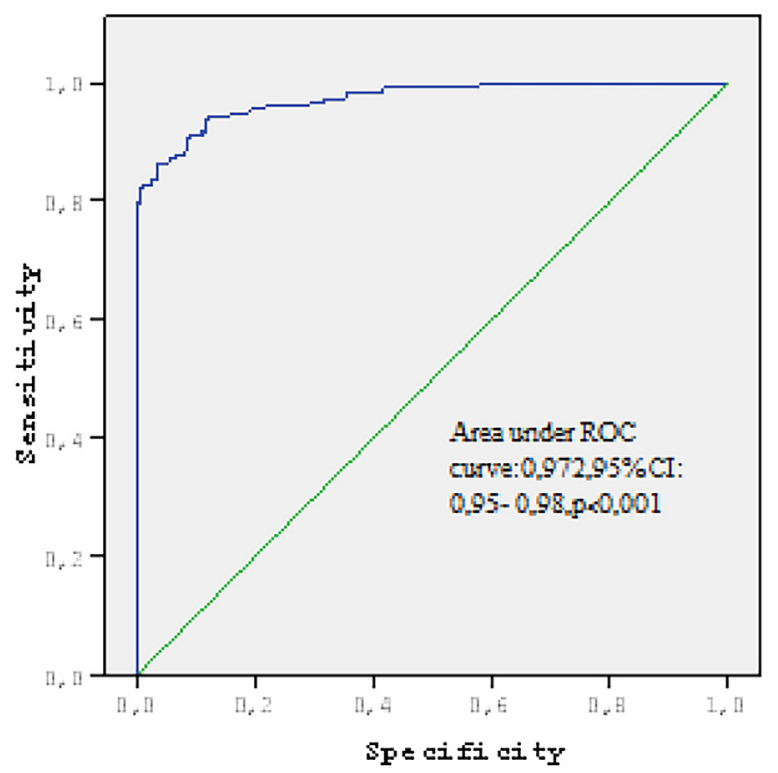

Fig. 2 - Receiver operating characteristic curve of MHR and 30-day mortality in acute ischemic stroke patients.

Monocytes, which play a particularly important role in prognosis after AIS, are recruited to the ischemic region [18]. This revealed several functional differences between monocyte subtypes in AIS. For example, an experimental rodent model showed that CCR2 ${ }^{+}$monocytes (Ly6C ${ }^{\text {high}}$ ) have proinflammatory effects, while Ly6 $\mathrm{C}^{\text {low }}$ monocytes are considered as anti-inflammatory patrolling monocytes [19]. Interestingly, the recruitment and infiltration of pro-inflammatory monocytes (Ly6C ${ }^{\text {high }}$ ) into ischemic brain tissue decreased over time (beginning at day 1 after AIS onset, peaked at day 3 and then declined at day 7), while the recruitment and infiltration of anti-inflammatory monocytes (Ly6C ${ }^{\text {low }}$ ) significantly increased [19]. Additionally, AIS modulates the peripheral immune response, triggering brain specific immune responses that directly affect the prognosis of AIS patients. A study by Kaito et al. revealed that the count of the classical monocyte subtype $\left(\mathrm{CD} 14^{++}, \mathrm{CD} 16^{-}\right)$, which is the equivalent of the rodent pro-inflammatory monocyte subtype (Ly6C ${ }^{\text {high }}$ ), was significantly increased in peripheral blood circulation, whereas the count of the non-classical monocyte subtype, which is the equivalent of the rodent anti-inflammatory monocyte subtype
(Ly6 $\mathrm{C}^{\text {low }}$ ), significantly decreased in the acute phase of AIS, which is strongly correlated with the progression and severity of brain infarction [20]. In addition, clinical studies have shown that the increased count of classical monocytes, which begin to increase in the peripheral blood circulation within $3 \mathrm{~h}$ after AIS onset was associated with the severity of brain injury [19]. Therefore, it can be suggested that the prognosis of AIS patients with high monocyte counts at admission may be worse than others, a finding similar to the results of our study.

Anti-inflammatory, antioxidant and antithrombotic effects of HDL have been proven in several studies [21,22]. HDL, which is classically regarded as an anti-atherogenic lipoprotein, prevents cholesterol transport to the arterial wall, especially in the lipid-laden macrophages [23]. In addition, HDL inhibits endothelial expression of adhesion molecules and effectively prevents monocyte adhesion to the arterial wall. HDL can also restrain the inflammatory response directly via monocytes [24]. In an experimental study, Murphy et al., demonstrated that HDL and its major protein component, apolipoprotein A-1, showed anti-inflammatory effects on human monocytes through the inhibition of the activation of CD 11b [24]. Therefore, it would not be wrong to suggest that high levels of HDL cholesterol may have direct protective effects against atrial myocytes through increased reverse cholesterol transport and indirect effects by increasing the anti-inflammatory and antioxidant effects, which could explain the suppression of AF development [10]. Consistent with these data, the HDL level in patients with AIS was found to be statistically lower than that of the control group in our study. In addition, it has also been found that the lower levels of HDL are closely related to mortality in some critical diseases [25]. Similarly, our study showed that lower HDL levels correlated with mortality in AIS patients.

The MHR value, defined as the division of monocyte count to HDL value, is a recently detected inflammatory indicator; however, its association with cardiovascular diseases and mortality has only been demonstrated in a few studies [26]. Kanbay et al. demonstrated that the increased value of MHR is an independent risk factor for worsening cardiovascular events in patients with chronic renal failure [9]. A study by Karatas suggested that high levels of MHR was independently correlated with in-hospital major adverse cardiac events (MACEs) and mortality after primary percutaneous coronary intervention in patients with ST-segment elevation myocardial infarction [27]. However, to date, there have been no published studies demonstrating the association between MHR and prognosis in AIS patients. Based on the literature and results obtained from our study, we can suggest that a high MHR value at admission may be an independent predictor of the 30-day mortality in AIS patients. An MHR value above 17.52 obtained via ROC curve analysis was the cut-off value for predicting the 30-day mortality in AIS.

The underlying mechanisms between high MHR levels and the 30-day mortality in AIS are not clearly understood, but as mentioned above, it is known that monocytes act in the proinflammatory direction during the acute phase of AIS, while HDL acts in the anti-inflammatory direction. Moreover, recent studies have suggested that inflammatory processes following brain injury after AIS may contribute to a poor outcome $[3,4,19,20]$. 
Our study is a single-center retrospective study and has some limitations. The only end point is the 30-day mortality in AIS. There was no detailed evaluation according to the etiologic subtypes of AIS or causes of 30-day mortality. Only one MHR value was used in the current study; however, the inflammatory process has continuity. The number of patients is relatively small because our study is a one-centered study. For these reasons, more detailed and extensive prospective studies are needed in the future.

In conclusion, we suggest that patients with AIS have higher monocyte counts, lower HDL levels, and therefore, higher MHR values compared to the control group. We also suggest that an MHR value above 17.52 is an independent risk factor for the 30-day mortality of AIS patients. Further extensive studies are required regarding this issue.

\section{Conflict of interest}

None declared.

\section{Acknowledgement and financial support}

None declared.

\section{R E F E R E N C E S}

[1] Balkan S, editor. 3rd ed., Serebrovaskuler hastaliklar, vols. 49-61, 3rd ed. Ankara; 2002. p. 236-55.

[2] Johnson RT, Griffin JW, McArthur JC, Saver JL. Current therapy in neurologic disease. 7th ed. Baltimore; 2002. p. 200-10.

[3] Fassbender K, Rossol S, Kammer T, Daffertshofer M, Wirth $\mathrm{S}$, Dollman M, et al. Proinflammatory cytokines in serum of patients with acute cerebral ischemia: Kinetics of secretion and relation to the extent of brain damage and outcome of disease. J Neurol Sci 1994;122:135-9.

[4] Hansson GK, Libby P, Schonbeck U, Yan ZQ. Innate and adaptive immunity in the pathogenesis of atherosclerosis. Circ Res 2002;91:281-91.

[5] Kazmierski R, Guzik P, Ambrosius W, Ciesielska A, Moskal J, Kozubski W. Predictive value of white blood cell count on admission for in-hospital mortality in acute stroke patients. Clin Neurol Neurosurg 2004;107:38-43.

[6] Olivares R, Ducimetière P, Claude JR. Monocyte count: a risk factor for coronary heart disease? Am J Epidemiol 1993;137 (1):49-53.

[7] Murphy AJ, Westerterp M, Yvan-Charvet L, Tall AR. Antiatherogenic mechanisms of high density lipoprotein: effects on myeloid cells. Biochim Biophys Acta 2012;1821:513-21.

[8] Hafiane A, Genest J. High density lipoproteins: measurement techniques and potential biomarkers of cardiovascular risk. BBA Clin 2015;3:175-88.

[9] Kanbay M, Solak Y, Unal HU, Kurt YG, Gok M, Cetinkaya H, et al. Monocyte count/HDL cholesterol ratio and cardiovascular events in patients with chronic kidney disease. Int Urol Nephrol 2014;46(8):1619-25.

[10] Canpolat U, Aytemir K, Yorgun H, Sahiner L, Kaya EB, Çay S, et al. The role of preprocedural monocyte-to-high-density lipoprotein ratio in prediction of atrial fibrillation recurrence after cryoballoon-based catheter ablation. Europace 2015;17(12):1807-15.

[11] Canpolat U, Çetin EH, Cetin S, Aydin S, Akboga MK, Yayla C, et al. Association of monocyte-to-HDL cholesterol ratio with slow coronary flow is linked to systemic inflammation. Clin Appl Thromb Hemost 2015;22(5):476-82.

[12] Ancuta P, Wang J, Gabuzda D. CD16 monocytes produce IL6 , CCL2, and matrix metalloproteinase-9 upon interaction with CX3CL1-expressing endothelial cells. J Leukoc Biol 2006;80:1156-64.

[13] Steinberg D, Witztum JL. Is the oxidative modification hypothesis relevant to human atherosclerosis? Do the antioxidant trials conducted to date refute the hypothesis? Circulation 2002;105:2107-11.

[14] Moreno PR, Purushothaman KR, Fuster V, O'Connor WN. Intimomedial interface damage and adventitial inflammation is increased beneath disrupted atherosclerosis in the aorta: implications for plaque vulnerability. Circulation 2002;105:2504-11.

[15] Lambert JM, Lopez EF, Lindsey ML. Macrophage roles following myocardial infarction. Int J Cardiol 2008;130:147-58.

[16] Fontes ML, Mathew JP, Rinder HM, Zelterman D, Smith BR, Rinder CS, Multicenter Study of Perioperative Ischemia Research Group. Atrial fibrillation after cardiac surgery/ cardiopulmonary bypass is associated with monocyte activation. Anesth Analg 2005;101:17-23.

[17] Karabacak M, Kahraman F, Sert M, Celik E, Adali MK, Varol E. Increased plasma monocyte chemoattractant protein-1 levels in patients with isolated low high density lipoprotein cholesterol. Scand J Clin Lab Invest 2015;75(4):327-32.

[18] Jin R, Yang G, Li G. Inflammatory mechanisms in ischemic stroke: role of inflammatory cells. J Leukoc Biol 2010;87:779-89.

[19] Kim E, Yang J, Beltran CD, Cho S. Role of spleen-derived monocytes/macrophages in acute ischemic brain injury. J Cereb Blood Flow Metab 2014 2014;34:1411-9.

[20] Kaito M, Araya S, Gondo Y, Fujita M, Minato N, Nakanishi M, et al. Relevance of distinct monocyte subsets to clinical course of ischemic stroke patients. PLOS ONE 2013;8(8): e69409. http://dx.doi.org/10.1371/journal.pone.0069409

[21] Barter PJ, Nicholls S, Rye KA, Anantharamaiah GM, Navab M, Fogelman AM. Antiinflammatory properties of HDL. Circ Res 2004;95:764-72.

[22] Cockerill GW, Rye KA, Gamble JR, Vadas MA, Barter PJ. Highdensity lipoproteins inhibit cytokine-induced expression of endothelial, cell adhesion molecules. Arterioscler Thromb Vasc Biol 1995;15:1987-94.

[23] Zhang Y, Zanotti I, Reilly MP, Glick JM, Rothblat GH, Rader DJ. Overexpression of apolipoprotein A-I promotes reverse transport of cholesterol from macrophages to feces in vivo. Circulation 2003;108:661-3.

[24] Murphy AJ, Woollard KJ, Hoang A, Mukhamedova N, Stirzaker RA, McCormick SP, et al. High density lipoprotein reduces the human monocyte inflammatory response. Arterioscler Thromb Vasc Biol 2008;28:2071-7.

[25] Gordon BR, Parker TS, Levine DM, Saal SD, Wang JC, Sloan BJ, et al. Low lipid concentrations in critical illness: implications for preventing and treating endotoxemia. Crit Care Med 1996;24(4):584-9.

[26] Zhang Y, Li S, Guo YL, Wu NQ Zhu CG, Gao Y, et al. Is monocyte to HDL ratio superior to monocyte count in predicting the cardiovascular outcomes: evidence from a large cohort of Chinese patients undergoing coronary angiography. Ann Med 2016;48(5):305-12.

[27] Karatas MB, Canga Y, Ozcan KS, Ipek G, Gungor B, Onuk T, et al. Monocyte to high-density lipoprotein ratio as a new prognostic marker in patients with STEMI undergoing primary percutaneous coronary intervention. Am J Emerg Med 2016;34(2):240-4. 